\title{
Effects of Pregnancy and Delivery in Women with Previous Surgery for Stress Urinary Incontinence with Suburethral Band: A Bibliographic Review
}

\author{
Natalia Gennaro Della Rossa*, Maria Victoria Herranz Izquierdo, Myriam Gracia Segovia, \\ Francisco Javier Plaza Arranz
}

University Hospital Fundación Jiménez Díaz, Madrid, Spain

Email: "nataliagennaro@hotmail.com

Received 12 May 2015; accepted 13 December 2015; published 16 December 2015

Copyright (C) 2015 by authors and Scientific Research Publishing Inc.

This work is licensed under the Creative Commons Attribution International License (CC BY). http://creativecommons.org/licenses/by/4.0/

(c) (i) Open Access

\section{Abstract}

The continence status and the most adequate form of delivery were assessed in pregnant women who had a suburethral band to treat stress urinary incontinence (SUI). A group of 57 women selected from different articles published between 2000 and 2014 were reviewed. These women had become pregnant after having undergone a suburethral band procedure. Different aspects such as age, parity, type of band, time elapsed between the procedure and the pregnancy, SUI during pregnancy and after delivery, and the form of delivery were evaluated, as well as the possible relationship with the recurrence of SUI and the emergence of complications associated with the suburethral during pregnancy. A case of a complication related to a suburethral band was found in one patient who developed an episode of pyelonephritis and intermittent urethral obstruction which required a Foley catheter. Thirty patients had cesarean section while 27 had vaginal deliveries; 12 patients had incontinence during pregnancy and 15 suffered from it after delivery. Postpartum SUI in relation with the delivery form did not show statistically relevant differences between the cesarean section group and the vaginal delivery group. It was observed that the emergence of SUI during pregnancy was a risk factor for the onset of postpartum SUI (OR $=6.47 ; p=$ 0.0137). The risk of developing postpartum SUI seems similar regardless the delivery form, thus it is plausible to recommend vaginal delivery to these patients. If there was a recurrence of SUI, a second suburethral band could be placed which would be as effective as the first one and would

${ }^{*}$ Corresponding author. 
involve a lower risk surgery compared to a cesarean section.

\section{Keywords}

\section{Stress Urinary Incontinence, Pregnant, Suburethral Band, TOT, TVT}

\section{Introduction}

Urinary incontinence is a pathology frequently found among women in general and with a prevalence ranging from 26 to 57 percent, with $50 \%$ of the cases found in SUI; $40 \%$ in mixed urinary incontinence and $10 \%$ in urgency urinary incontinence [1]-[3]. The onset of the symptoms peaks at ages between 45 and 49 years, although the prevalence in women younger than 40 [4] years is $8.1 \%$. Parity, and mainly the first delivery, contributes greatly to the development of SUI. It has been proved that multiparous women with SUI, experience changes in the elastic properties of the fascial structures, with a decrease of collagen Type 1 and an increased mobility of the bladder neck if compared to continent women [5] [6]. In fact, between the ages of 20 and 34 the association between the first delivery and SUI is stronger, with a relative risk of 2.2 [7]. This is the reason why a treatment for urinary incontinence is frequently needed in earlier ages even when the genesic desire has not been fulfilled yet. Initially, a conservative treatment would be indicated with behavioral measures, medications and physiotherapy, as needed; considering the surgical treatment as an option if the first one failed.

During pregnancy, apart from the possible changes that may appear due to previous deliveries, there is an enlargement in the uterus with the consequent decrease in bladder capacity and a weight increase which favor the development of symptoms in the lower urinary tract.

The prevalence of SUI increases during pregnancy, being SUI presence in the $12^{\text {th }}$ week of gestation the most determining factor for SUI development in the first year after delivery. In addition, the delivery form also contributes to SUI development, being vaginal delivery the most prevalent. Despite all these, it is necessary to take into account that most women show a spontaneous recovery in 6 - 12 months after delivery.

It is very important to bear in mind that a lesion may occur at the pelvic floor during vaginal delivery due to tearing, episiotomy, distention or nerve damage, either direct or indirect; and special attention must be paid not to overlook an anal lesion. Dietz and Lazarone [8] [9] objectified through ultrasound examination the presence of a hidden lesion at the pelvic floor in $36 \%$ of first-time mothers after vaginal deliveries. This is very important because SUI appears in $43 \%$ of women with avulsion of the anus levator muscle while it appears in $11 \%$ of women without lesions in the muscle.

There is not much knowledge about the influence of pregnancy and delivery in women who have been operated on due to SUI. Thus, a bibliographic review has been carried out in order to assess continence in women who have given birth after the placement of a suburethral band to treat incontinence, the possible consequences associated to the procedure and the most adequate delivery form.

\section{Methods and Materials}

An exhaustive bibliographic review was carried out through Pubmed. The review included [10]-[25] case series, case reports and article reviews (Table 1), using the following key words: SUI, suburethral band, TVT, TOT, pregnancy, vaginal delivery and caesarean section. Cases of women with successful full-term pregnancies were included. The patient inclusion criteria was based on age, parity, type of band, the period between band placement and pregnancy, SUI presence during pregnancy and after delivery, delivery form and its possible connection with SUI recurrence, and the onset of complications related to the suburethral band during pregnancy.

In order to assess the postpartum SUI in terms of the delivery form, the Odds Ratio test was used; meanwhile, the Chi-squared test was used to calculate statistical significance. The calculation of SUI in terms of a previous presence during pregnancy was also done using the Odds Ratio test, but Fisher's exact test was used for frequency comparison and statistical significance. The parameters included age of surgery, parity, interval between surgery and subsequent pregnancy, the presence or absence of incontinence during pregnancy, and the delivery form. Statistical significance will be considered when $\mathrm{p}<0.5$. 
Table 1. Data of the 57 patients included in the review (2000-2014).

\begin{tabular}{|c|c|c|c|c|c|c|c|c|c|}
\hline Authors & $\mathrm{N}$ & Age & Parity & $\begin{array}{l}\text { Months from } \\
\text { surgery }\end{array}$ & $\begin{array}{c}\text { SUI in } \\
\text { pregnancy }\end{array}$ & Complications & $\begin{array}{l}\text { Delivery } \\
\text { form }\end{array}$ & $\begin{array}{c}\text { Post } \\
\text { partum SUI }\end{array}$ & $\begin{array}{c}\text { Follow-up } \\
\text { (months) }\end{array}$ \\
\hline $\begin{array}{l}\text { Iskander } \\
\text { et al. [10] }\end{array}$ & 1 & 34 & 2 & 9 & no & no & Cs & no & 6 \\
\hline $\begin{array}{c}\text { Lynch } \\
\text { et al. [11] }\end{array}$ & 1 & 26 & 2 & 1 & no & yes & Cs & yes & 3 \\
\hline $\begin{array}{l}\text { Gaurunder } \\
\text { et al. [12] }\end{array}$ & 1 & 39 & 4 & 3 & no & no & Cs & no & 2 \\
\hline $\begin{array}{c}\text { Vella } \\
\text { et al. [13] }\end{array}$ & 2 & 42 & 2 & 42 & no & no & 1VD $1 \mathrm{Cs}$ & no & 30 \\
\hline $\begin{array}{l}\text { Hassan } \\
\text { et al. [14] }\end{array}$ & 1 & 36 & 1 & -1 & no & no & VD & no & 2 \\
\hline $\begin{array}{l}\text { Panel } \\
\text { et al. [15] }\end{array}$ & 15 & 33 & 4 & $19.9 \pm 14.9$ & 12 no 3 yes & no & 7 cs 8 vd & 12 no 3 yes & $14.6 \pm 14$ \\
\hline $\begin{array}{l}\text { Groenen } \\
\text { et al. [16] }\end{array}$ & 3 & $33 \pm 5$ & 2 & $11 \pm 11.3$ & 2 no 1 yes & no & $1 \mathrm{cs} 2 \mathrm{vd}$ & 1 no 2 yes & \\
\hline $\begin{array}{l}\text { Caykaytar } \\
\text { et al. [17] }\end{array}$ & 12 & $33.1 \pm 4.32$ & 5 & $30.2 \pm 14.2$ & 12 no 3 yes & no & 7 cs 5 vd & 10 no 2 yes & \\
\hline $\begin{array}{l}\text { Sergent } \\
\text { et al. [18] }\end{array}$ & 1 & 38 & 1 & 12 & no & no & vd & yes & \\
\hline $\begin{array}{l}\text { Demaria } \\
\text { et al. [19] }\end{array}$ & 1 & 43 & 3 & 12 & no & no & vd & yes & \\
\hline $\begin{array}{l}\text { El-Ghobashy } \\
\text { et al. [20] }\end{array}$ & 1 & 37 & 2 & 1 & yes & no & vd & no & \\
\hline $\begin{array}{l}\text { Kohorst } \\
\text { et al. [21] }\end{array}$ & 1 & 26 & 2 & 2 & no & no & CS & no & \\
\hline $\begin{array}{l}\text { Sedlakova } \\
\text { et al. [22] }\end{array}$ & 2 & $30.5 \pm 2.12$ & 4 & $30 \pm 8.49$ & no & no & $2 \mathrm{vd}$ & no & \\
\hline $\begin{array}{l}\text { Adams-piper } \\
\text { et al. [23] }\end{array}$ & 15 & $33.5 \pm 4.66$ & 4 & $27.4 \pm 18.65$ & 11 no 4 yes & no & 10 cs 5 vd & 9 no 6 yes & $24.4 \pm 13.1$ \\
\hline
\end{tabular}

CS: Caesarean Section; VD: Vaginal Delivery.

\section{Results}

The review included 62 patients who had given birth after the adequate placement of a suburethral band to treat SUI. Five patients were ruled out due to lack of information (two patients because age and moment of surgery were unknown, one patient because moment of surgery was unknown, one patient without information about postpartum continence and the last one due to lack of information about continence during pregnancy). Thus, the study was carried out with 57 patients. The average age at the moment of surgery was $33.84 \pm 4.92$ years and the time elapsed between surgery and a subsequent pregnancy was $22.71 \pm 16.67$ months. All the women were multiparous, 82.4\% ( $\mathrm{N}=47)$ had had between two and five deliveries, and had a suburethral band (TVT, TOT, mini-sling or anterior IVS). The probability of presenting urinary incontinence during pregnancy was $21.1 \%(\mathrm{~N}=$ 12) while the percentage of complications was $1.8 \%(\mathrm{~N}=1$; one patient had an episode of pyelonephritis and intermittent urethral obstruction which required the placement of a Foley's catheter). The delivery form was through elective cesarean section in 30 women whereas 27 had vaginal delivery; out of them, 15 women had postpartum SUI (26.3\%).

If the above data are analyzed in more detail, and as shown in Table 2, it can be observed that for the patients with a cesarean section the SUI probability was 23.3\% $(\mathrm{N}=7)$, whereas the probability was $29.6 \%(\mathrm{~N}=8)$ for patients who had vaginal deliveries. Thus, it seems that patients who had vaginal deliveries were at higher risk of having SUI. If one Odds ratio is calculated on the basis of the frequencies shown in the table, the result is 1.38, that is, patients with vaginal delivery have 38\% higher risk of postpartum SUI than patients with cesarean section. Nevertheless, this difference is not statistically significant because if the frequencies are compared by means of the Chi-squared test, the result is a $\mathrm{P}$ of 0.812 . Therefore, although a difference can be seen, it cannot be concluded that the delivery form is related with SUI incidence. 
Table 2. SUI frequency after delivery according to delivery form.

\begin{tabular}{cccc}
\hline Delivery form & No pospartum SUI & Postpartum SUI & total \\
\hline \multirow{2}{*}{ caesarean section } & 23 & 7 & 30 \\
& $76.70 \%$ & $23.30 \%$ & 27 \\
\hline
\end{tabular}

Table 3. Frequency of SUI after delivery according to SUI during pregnancy.

\begin{tabular}{cccc}
\hline SUI in pregnancy & No postpartum SUI & Postpartum SUI & Total \\
\hline NO & 37 & 8 & 45 \\
& $82.20 \%$ & $23.30 \%$ & 7 \\
Yes & 5 & $58.30 \%$ & 12 \\
\hline
\end{tabular}

If the relationship between the presence of SUI during pregnancy and after delivery is observed, it can be seen that for the patients who did not have SUI during pregnancy the probability of suffering postpartum SUI is $17.8 \%$. On the other hand, for those who had SUI during pregnancy the probability of suffering postpartum SUI is $58.3 \%$ (Table 3). Thus, it seems that having SUI during pregnancy increases the risk of having it after delivery. If the Odds ratio is calculated at this point, the result would be 6.47; that is, the patients who had SUI during pregnancy have a risk 6.5 times higher of suffering postpartum SUI than the patients who did not have SUI during pregnancy. If the frequencies are compared by means of the Fisher's exact test the result would be a p of 0.0137. Thus, it can be said that having SUI during pregnancy increases the risk of having it after delivery.

\section{Discussion}

The management of SUI in women with unfulfilled genetic desire and the literature on the topic is very limited as well as the bibliography on the complications for this surgery during pregnancy.

In the review, only one case was found of a complication related to a suburethral band in a patient who developed an episode of pyelonephritis and intermittent urethral obstruction which required the placement of a Foley's catheter. Therefore, there could be a small increase in the risk of minor complications associated with the surgical mesh during pregnancy but it has not been observed to cause harm or fetal death.

On the other hand, we have seen that $21.1 \%$ of the cases $(\mathrm{N}=12)$ developed urinary incontinence during gestation, presupposing a risk 6.5 higher of developing postpartum SUI with $\mathrm{p}<0.05$. Thus, the presence of SUI is a risk factor for the development of postpartum SUI.

Concerning delivery form, the results are very similar with seven (7) patients developing postpartum SUI out of the 30 who underwent elective cesarean section; and eight (8) patients out of the 27 women who had vaginal delivery. Despite the percentage being higher in the vaginal-delivery group (29.6\% vs. $23.3 \%)$, the differences were not statistically significant. Taking into account the risks of a major surgery like a cesarean section, considering that the natural tendency of SUI after delivery is to spontaneously improve in 6 - 12 months, and also considering that the effectiveness of a second mesh is similar to the first one, with lesser risks in a minor surgery, it is plausible to recommend vaginal delivery to these patients although more studies are needed to indicate the best delivery form for patients with suburethral bands.

\section{References}

[1] Hannestad, Y.S., Rortveir, G., Sandvik, H. and Hunskaar, S. (2000) A Community-Based Epidemiological Survey of Female Urinary Incontinence: The Norwegian EPINCONT Study. Epidemiology of Incontinence in the Country of Nord-Trondelag. Journal of Clinical Epidemiology, 53, 1150-1157. http://dx.doi.org/10.1016/S0895-4356(00)00232-8 
[2] Rekers, H., Drogendijk, A.C., Valkenburg, H. and Riphagen, F. (1992) Urinary Incontinence in Women from 35 to 79 Years of Age: Prevalence and Consequences. European Journal of Obstetrics \& Gynecology and Reproductive Biology, 43, 229-234. http://dx.doi.org/10.1016/0028-2243(92)90178-2

[3] Van der Vaart, C.H., de Leeuw, J.R., Roovers, J.P. and Heintz, A.P. (2000) The Influence of Urinary Incontinence on Quality of Life of Community-Dwelling, 45-70-Year Old Dutch Women. Nederlands Tijdschrift Voor Geneeskunde, 144, 894-897.

[4] Pyrat, L., Haillot, O., Bruyere, F., Boutin, J.M., Bartrand, P. and Lanson, Y. (2002) Prevalence and risk factors of urinary incontinence in Young and middle-aged Women. BJU International, 89, 61-66. http://dx.doi.org/10.1046/j.1464-410X.2002.02546.x

[5] Kean, D.P., Sims, T.J., Abrams, P. and Bailey, A.J. (1997) Analysis of Collagen Status in Premenopausal Nulliparous Women with Genuine Stress Incontinence. BJOG, 104, 994-998. http://dx.doi.org/10.1111/j.1471-0528.1997.tb12055.x

[6] King, J.K. and Freeman, R.M. (1998) Is Antenatal Bladder Neck Mobility a Risk Factor for Postpartum Stress Incontinence. BJOG, 105, 1300-1307. http://dx.doi.org/10.1111/j.1471-0528.1998.tb10009.x

[7] Rortveit, G., Hannestad, Y.S., Daltveir, A.K. and Hunskaar, S. (2001) Age- and Type-Dependent Effects of Parity on Urinary Incontinence: The Norwegian EPINCONT Study. Obstetrics \& Gynecology, 98, 1004-1010. http://dx.doi.org/10.1016/S0029-7844(01)01566-6

[8] Van Brummen, H.J., Bruinse, H.W., Van Der Bom, J.G., Heintz, A.P. and Van Der Vaart, C.H. (2006) How Do the Prevalences of Urogenital Symptoms Change during Pregnancy. Neurourology and Urodynamics, 25, 135-139. http://dx.doi.org/10.1002/nau.20149

[9] Dietz, H.P. and Lanzarone, V. (2005) Levator Trauma after Vaginal Delivery. Obstetrics \& Gynecology, 106, $707-712$. http://dx.doi.org/10.1097/01.AOG.0000178779.62181.01

[10] Iskander, M.N. and Kapoor, D. (2000) Pregnancy Following Tension-Free Vaginal Taping. International Urogynecology Journal, 11, 199-200. http://dx.doi.org/10.1007/s001920070049

[11] Lynch, C.M., Powers, A.K. and Keating, A.B. (2001) Pregnancy Complicated by a Suburethral Sling: A Case Report. International Urogynecology Journal, 12, 218-219. http://dx.doi.org/10.1007/s001920170067

[12] Gaurunder-Burmester, A. and Tunn, R. (2001) Pregnancy and Labor after TVT-Plasty. Acta Obstetricia et Gynecologica Scandinavica, 80, 283-284. http://dx.doi.org/10.1034/j.1600-0412.2001.080003283.x

[13] Vella, M., Robinson, D., Brown, R. and Cardozo, L. (2007) Pregnancy and Delivery Following Tension-Free Vaginal Tape. International Urogynecology Journal, 18, 347-348.

[14] Hassan, M.S., Yossri, N. and Davies, A. (2007) Vaginal Delivery after Surgical Treatment for Stress Incontinence Using Trasobturator Tape: A Case Report. BJOG, 114, 113-114.

[15] Panel, L., Triopon, G., Courtieu, C., Marès, P. and de Tayrac, R. (2008) How to Advise a Woman Who Wants to Get Pregnant after a Sub-Urethral Tape Placement? International Urogynecology Journal, 19, 347-350. http://dx.doi.org/10.1007/s00192-007-0444-3

[16] Groenen, R., Vos, M.C., Willekes, C. and Vervest, H.A. (2008) Pregnancy and Delivery after Mid-Urethral Sling Procedures for Stress Urinary Incontinence: Case Reports and a Review of Literatura. International Urogynecology Journal, 19, 441-448. http://dx.doi.org/10.1007/s00192-007-0509-3

[17] Cavkaytar, S., Kokanali, M.K., Ozer, I., Erkilinc, S., Aksakal, O.S. and Doganay, M. (2015) Effect of Pregnancy and Delivery on Urinary Incontinence after the Midurethral Sling Procedure. International Urogynecology Journal, 26, 693-698.

[18] Sergent, F. and Marpeau, L. (2007) Recurrence of Stress Urinaty Incontinence after Tension-Free Vaginal Tape and Childbirth. Gynécologie Obstétrique \& Fertilité, 35, 1239-1241. http://dx.doi.org/10.1016/j.gyobfe.2007.10.010

[19] Demaria, F., Chanelles, O., Boquet, B., Bricou, A., Amarenco, G. and Benifla, J.L. (2007) Vaginal delivery after tensión-free vaginal tape procedure. International Urogynecology Journal, 18, 1363-1365. http://dx.doi.org/10.1007/s00192-007-0352-6

[20] El-Ghobashy, A., Haw, W., Brook, G. and Clavert, S. (2007) Pregnancy after TVT-O Case Report and Literature Review. International Urogynecology Journal, 18, 1491-1493. http://dx.doi.org/10.1007/s00192-007-0377-X

[21] Kohorst, F., Flock, F., Kreienberg, R. and Reich, A. (2010) Pregnancy and Delivery after Tension-Free Vaginal Tape (TVT) Procedure: Literatura Review and Case Report. European Journal of Obstetrics \& Gynecology and Reproductive Biology, 151, 10-13. http://dx.doi.org/10.1016/j.ejogrb.2010.03.020

[22] Sedlakova, K., Huser, M. and Belkov, I. (2011) Vaginal Delivery after Tension-Free Vaginal Tape Insertion. Med. Prakt Gynecol., 15, 42-46. 
[23] Adams-Piper, E., Darbinian, J., Postlethwaite, D. and Castillo, P.A. (2014) Pregnancy after Transvaginal Sling for Stress Urinary Incontinence: A Case Series. Female Pelvic Medicine \& Reconstructive Surgery, 20, 212-215. http://dx.doi.org/10.1097/SPV.0000000000000096

[24] Glazener, C.M., Herbison, G.P., MacArthur, C., Grant, A. and Wilson, P.D. (2005) Randomised Controlled Trial of Conservative Management of Postnatal Urinary and Faecal Incontinence: Six Year Follow Up. BMJ, 330, 337. http://dx.doi.org/10.1136/bmj.38320.613461.82

[25] Riachi, L., Kohli, N. and Miklos, J. (2002) Repeat Tension-Free Transvaginal Tape (TVT) Sling for the Treatment of Recurrent Stress Urinary Incontinence. International Urogynecology Journal, 13, 133-135. http://dx.doi.org/10.1007/s001920200028 